\title{
DRD4 genotyping may differentiate symptoms of attention-deficit/hyperactivity disorder and sluggish cognitive tempo
}

\author{
Hilmi Bolat, ${ }^{1}$ iD Eyüp S. Ercan, ${ }^{2}$ Gül Ünsel-Bolat, ${ }^{3}$ Akın Tahıllıoğlu, ${ }^{2}$ Kemal U. Yazıcı, ${ }^{4}$ Ali Bacanlı, ${ }^{5}$ \\ Erhan Parıltay, ${ }^{6}$ Duygu Aygüneş Jafari, ${ }^{7}$ Buket Kosova, ${ }^{7}$ Semiha Özgül, ${ }^{8}$ Luis A. Rohde, ${ }^{9,10}$ \\ Haluk Akın 6

\begin{abstract}
${ }^{1}$ Department of Medical Genetics, Balıkesir Atatürk City Hospital, Balıkesir, Turkey. ${ }^{2}$ Department of Child and Adolescent Psychiatry, Ege University, Izmir, Turkey. ${ }^{3}$ Department of Child and Adolescent Psychiatry, Balıkesir University Faculty of Medicine, Balıkesir, Turkey. ${ }^{4}$ Department of Child and Adolescent Psychiatry, Firat University, Izmir, Turkey. ${ }^{5}$ Department of Child and Adolescent Psychiatry, Baskent University, Izmir, Turkey. ${ }^{6}$ Department of Medical Genetics, Ege University, Izmir, Turkey. ${ }^{7}$ Department of Medical Biology, Ege University, Izmir, Turkey. ${ }^{8}$ Department of Bioistatistics and Medical Informatics, Ege University, Izmir, Turkey. ${ }^{9}$ Programa de Transtornos de Déficit de Atenção/Hiperatividade (ProDAH), Hospital de Clínicas de Porto Alegre, Universidade Federal do Rio Grande do Sul, Porto Alegre, RS, Brazil. ${ }^{10}$ Instituto Nacional de Psiquiatria do Desenvolvimento para Crianças e Adolescentes, São Paulo, SP, Brazil.
\end{abstract}

\begin{abstract}
Objective: Studies to reduce the heterogeneity of attention-deficit/hyperactivity disorder (ADHD) have increased interest in the concept of sluggish cognitive tempo (SCT). The aim of this study was to investigate if the prevalence of two variable-number tandem repeats (VNTRs) located within the $3^{\prime}$-untranslated region of the DAT1 gene and in exon 3 of the dopamine D4 receptor (DRD4) gene differ among four groups (31 subjects with SCT but no ADHD, 146 individuals with ADHD but no SCT, 67 subjects with SCT + ADHD, and 92 healthy controls).

Methods: We compared the sociodemographic profiles, neurocognitive domains, and prevalence of two VNTRs in SCT and ADHD subjects versus typically developing (TD) controls.

Results: The SCT without ADHD group had a higher proportion of females and lower parental educational attainment. Subjects in this group performed worse on neuropsychological tests, except for psychomotor speed and commission errors, compared to controls. However, the ADHD without SCT group performed significantly worse on all neuropsychological domains than controls. We found that 4R homozygosity for the DRD4 gene was most prevalent in the ADHD without SCT group. The SCT without ADHD group had the highest 7R allele frequency, differing significantly from the ADHD without SCT group.

Conclusion: The 7R allele of DRD4 gene was found to be significantly more prevalent in SCT cases than in ADHD cases. No substantial neuropsychological differences were found between SCT and ADHD subjects.
\end{abstract}

Keywords: attention-deficit/hyperactivity disorder; sluggish cognitive tempo; dopamine transporter gene; dopamine receptor D4 gene; psychomotor speed

\section{Introduction}

Attention-deficit/hyperactivity disorder (ADHD) is a multifactorial, polygenic disease. Although the etiology and pathogenesis of ADHD are not fully understood, studies have shown that the heritability of ADHD is about $77-88 \% .^{1}$ Up to now, gene variants associated with the diagnosis of ADHD have explained only a very small part of the pathogenesis. Many different biological pathways have been investigated to identify a biomarker for ADHD. The dopaminergic pathway has been most studied in this approach, and is known to be associated with the

Correspondence: Hilmi Bolat, Balıkesir Atatürk City Hospital, Postal Code, 10100, Balıkesir. Turkey.

E-mail: hilmi.bolat.ege@gmail.com

Submitted Jul 27 2019, accepted Jan 17 2020, Epub Jun 012020. diagnosis and symptoms of ADHD. ${ }^{2}$ For the dopaminergic pathway, variants in dopamine transporter (DAT1, SLC6A3) and dopamine $\mathrm{D} 4$ receptor $(D R D 4)$ genes have been shown as the best candidates related to neuropsychological tasks and methylphenidate response. ${ }^{3}$

The most frequently studied variable-number tandem repeats (VNTR) in the DAT1 gene consists of 40 base pairs (bp) in the $3^{\prime}$-untranslated region ( $3^{\prime}$ UTR). Studies have found that the $10 \mathrm{R}$ allele of DAT1 is associated with impaired performance of neurocognitive tests, increases DAT protein density in the basal ganglia, and decreases the amount of dopamine in the synaptic cleft, especially in

How to cite this article: Bolat $H$, Ercan $E S$, Ünsel-Bolat $G$, Tahıllıoğlu A, Yazıcı KU, Bacanlı A, et al. DRD4 genotyping may differentiate symptoms of attention-deficit/hyperactivity disorder and sluggish cognitive tempo. Braz J Psychiatry. 2020;42:630-637. http://dx.doi.org/10.1590/1516-4446-2019-0630 
ADHD subjects. ${ }^{4-6}$ Also, pharmacogenetic studies have shown that 10R homozygosity was associated with reduced response to methylphenidate treatment. ${ }^{7}$

Another important candidate biomarker for ADHD is $D R D 4$. This gene is highly expressed in regions such as the anterior cingulate cortex, which is known to be associated with attention and inhibitory behavior of the brain. ${ }^{6}$ There is a highly polymorphic functional VNTR in DRD4, consisting of $48 \mathrm{bp}$ in exon 3 , which is frequently studied in ADHD. Different DRD4 genotypes have been shown to be associated with differential treatment response in pharmacogenetic studies. It has been suggested that the 7R allele can encode a defective dopamine receptor gene, thus reducing treatment response. In addition, some previous reports suggest that ADHD subjects with the $7 R$ allele may even constitute a subgroup with different characteristics. $3,8,9$

A consortium of ADHD researchers conducted a genome-wide association study (GWAS) of 12 studies including 20,183 cases diagnosed with ADHD and 35,191 healthy controls. ${ }^{10}$ As its name implies, a GWAS examines the entire genome to find common DNA variants by scanning thousands or even millions of single nucleotide polymorphisms (SNPs). ${ }^{11}$ In this GWAS, variants surpassing genome-wide significance were described in 12 independent loci, but the DAT1 and DRD4 genes, pointed out in previous case-control research, were not associated with ADHD in this study. Nevertheless, it is important to keep in mind that the structure of a VNTR causes technical problems during SNP genotyping in array platforms, which complicates scoring of the number of repeats present. ${ }^{12}$

Discovery of disease-specific biomarkers has proved particularly elusive in psychiatric disorders. A key reason for this is the heterogeneous nature of psychiatric disorders, with multiple subtypes and protean clinical manifestations, even in patients with the same diagnosis. There is a clear need for studies to reduce phenotypic heterogeneity. One promising area of research for reducing such heterogeneity specifically in ADHD focuses on the concept of sluggish cognitive tempo (SCT). Some investigators claim that SCT might be an independent phenotype from ADHD, and that symptoms of this potential new diagnosis might be erroneously placed under the diagnostic umbrella of ADHD. ${ }^{13}$ Especially since 2010, studies have revealed different features of SCT in terms of sociodemographic characteristics, neuropsychological findings, symptom features, comorbidities, and treatment response. ${ }^{13}$

SCT is characterized by daydreaming, mental confusion, staring blankly, and hypoactivity. The prevalence of SCT was reported at around $11 \%$ in an epidemiological study in children. ${ }^{14}$ The most important finding of the large number of studies in this area is that SCT seems to be not a subtype of ADHD, but a separate disorder that is frequently associated with ADHD. ${ }^{15-17}$ Also, some investigators suggest that SCT might be a second inattention disorder, which might be named "concentration deficit disorder." 15 SCT and ADHD might even affected by different attention pathways. There are only two published neuroimaging studies investigating SCT symptoms. In the first study, higher SCT symptoms were associated with hypoactivity in the left superior parietal lobe, while higher inattention symptoms were associated with altered activity in the supplementary motor area and thalamus on cognitive control-related functional magnetic resonance imaging (fMRI). ${ }^{18}$ The second study found that subjects with SCT symptoms had increased frontal-lobe volume and less segregation in the two major networks (posterior cingulate cortex and dorsal frontal region)..$^{19}$ However, we are not aware of any genetic study comparing SCT and ADHD subjects to understand potential different etiologic pathways, except for a twin study which detected SCT symptoms as less heritable than ADHD symptoms. ${ }^{20}$

The main aim of this study was to investigate the prevalence of two VNTRs (located within the 3' UTR region of $D A T 1$ and in exon 3 of DRD4) and neuropsychological findings among four groups: SCT without ADHD, ADHD without SCT, SCT + ADHD, and typically developing (TD) controls.

\section{Methods}

\section{Subjects}

Patients were screened with the SCT-Child Behavior Checklist (CBCL) in the outpatient clinic of the child and adolescent psychiatry department of Ege University, Turkey. After the screening procedure, 31 SCT without ADHD, 67 SCT + ADHD, 146 ADHD without SCT, and 92 TD subjects were included in this study.

The inclusion criteria were: 1) age between 6 and 15 years; 2) living in family home and attending regular school; 3) no intellectual disability at the clinical level; 4) no neurological disease; 5) no substance-alcohol use disorder; and 6) no history of perinatal complications or head trauma. The inclusion criteria for the TD group were the same, except that absence of ADHD and SCT was required.

\section{Diagnostic procedures}

Screening for possible SCT symptoms was applied to all children referred to the outpatient clinic of the child and adolescent psychiatry department. For this screening procedure, parents were asked to score four SCT items from the CBCL (confused/seems in a fog, daydreams, stares blankly, and underactive). Subsequently, a child and adolescent psychiatrist interviewed the parents and children to assess SCT and ADHD diagnoses using standard diagnostic procedures and DSM-IV criteria. ${ }^{21}$ At the same evaluation, parents completed the Barkley Child Attention Survey (BCAS), CBCL, and the Attention-Deficit/ Hyperactivity Disorder Rating Scale-IV (ADHD-RS-IV). All diagnostic procedures are described in Figure 1.

\section{Instruments}

The CBCL is a standardized parent-report questionnaire designed by Achenbach to assess emotional and behavioral problems and social competencies in children. It has good validity and reliability. ${ }^{22}$ The CBCL has eight subscales (withdrawn, somatic complaints, anxiety/depression, 


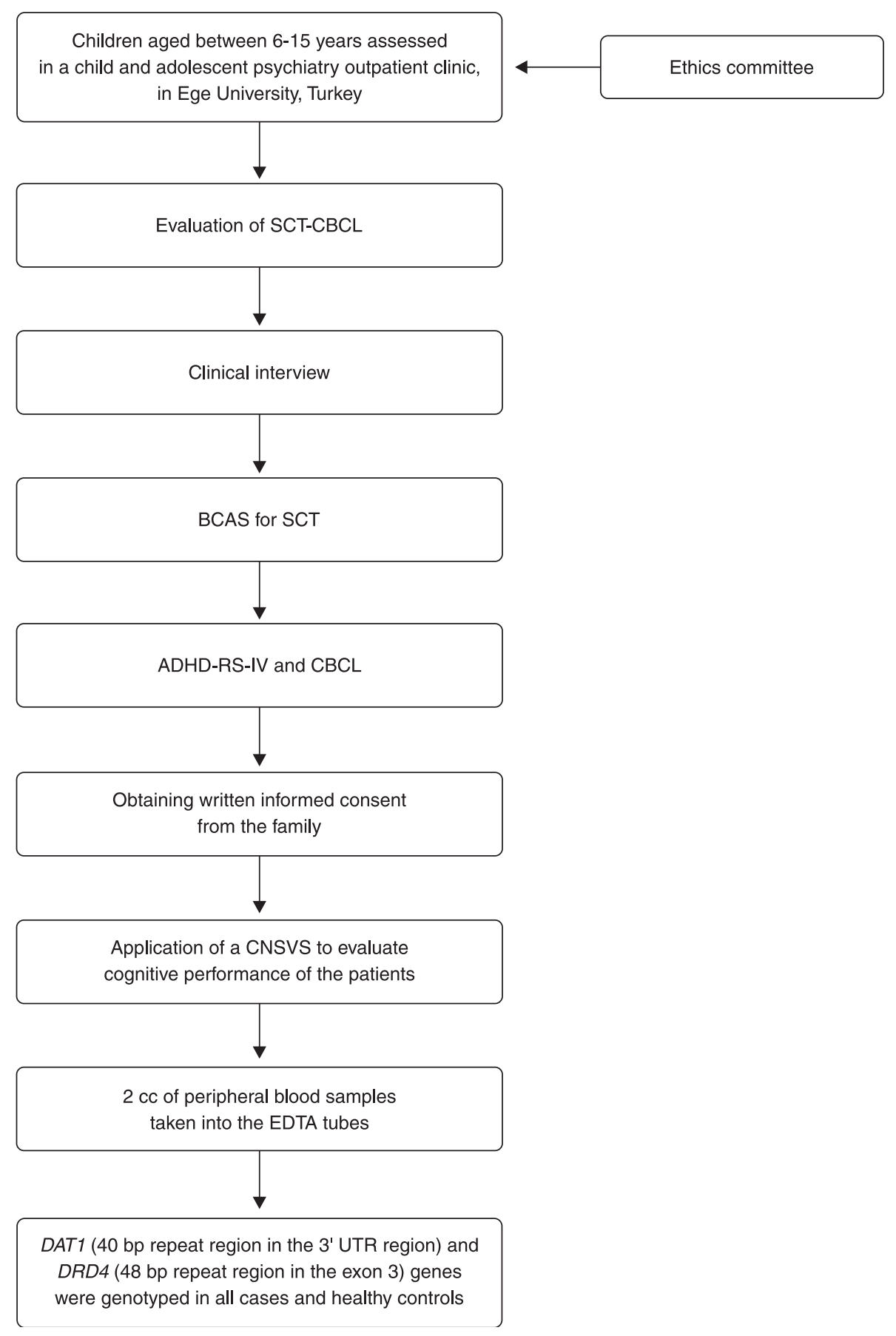

Figure 1 Flow diagram of study design and diagnostic procedures. ADHD-RS-IV = Attention-Deficit/Hyperactivity Disorder Rating Scale-IV; BCAS = Barkley's Child Attention Survey; $b p=$ base pair; CNSVS = Computerized Neurocognitive Assessment - Vital Signs; SCT = sluggish cognitive tempo; SCT-CBCL = Sluggish Cognitive Tempo-Child Behavior Checklist.

thought problems, attention problems, social problems, aggressive behavior, and delinquent behavior) and two broad domains: internalizing and externalizing problems. Back-translation, bilingual retest assessment, and a pretest field study were done for the CBCL-Turkish form. ${ }^{23}$

The ADHD-RS-IV ${ }^{24}$ is an 18-item questionnaire based on the diagnostic criteria for ADHD, as described in the DSM-IV. The ADHD-RS-IV provides inattention and hyperactivity-impulsivity scores, as well as a total score.
Scores are calculated by assigning a severity estimate to each symptom on a four-point Likert-type scale $(0=$ not at all; 1 = just a little; 2 = much; and $3=$ very much). Ratings of much and very much for each item were considered positive, as done in other similar investigations. The ADHD-RS-IV has shown adequate criterion validity and good reliability in different cultures, both for parent and teacher reports. ${ }^{24,25}$ We used the version translated and adapted into Turkish. ${ }^{26}$ 
The $\mathrm{BCAS}^{27}$ is a 12-item questionnaire that measures SCT symptoms. The symptoms are scored on a four-point Likert-type scale ranging from $1=$ never or rarely to $4=$ very often; the score should refer to the frequency of each item in the past 6 months. Reliability and validity of this scale were determined in North American children. ${ }^{27}$ Internal consistency (Cronbach's alpha) of the 12 items was 0.934 . Test-retest reliability was $r=0.84$. Translation into Turkish and back-translation were done by the authors of the present study according to standard procedures. The reliability and validity of the BCAS have been tested in Turkish children, and the internal consistency (Cronbach's alpha) of the 12 items was $0.86 .^{28}$

The Computerized Neurocognitive Assessment - Vital Signs (CNSVS) brief clinical evaluation battery consists of seven tests: verbal and visual memory, finger tapping, symbol digit coding, the Stroop test, a test of shifting attention, and the continuous performance test. The seven tests generate 17 primary scores and five domain scores. These domain scores are memory (derived from verbal and visual memory), psychomotor speed (from finger tapping and symbol-digit coding), reaction time (Stroop test), cognitive flexibility (Stroop test and shifting attention test), and complex attention (Stroop test, shifting attention test, and continuous performance test). Domain scores are generated as raw scores and then computed as standard scores for age. Standard scores have a mean of 100 , which represents the 50th percentile, and a standard deviation (SD) of 15. For standard scores, higher is always better (e.g., a lower standard score in the reaction time domain represents a slower response). A Neurocognition Index $(\mathrm{NCl})$ is also computed, representing the mean of the five domain scores. We also present findings for the Continuous Performance Test (CPT) scores separately. In this case, higher scores mean better performance for correct responses and taps; for errors and reaction times, lower scores are better (for more details on the tests, see Gualtieri \& Johnson ${ }^{29}$ ).

\section{Genotyping}

Genomic DNA was extracted from saliva or peripheral blood samples. Samples from all subjects were genotyped by a researcher who was blind to subjects' diagnoses. Genotyping of DRD4 and DAT1 was performed according to standard laboratory protocols. Briefly, DNA was extracted from saliva following manufacturer instructions (High Pure PCR Template Preparation Kit, Roche) or from peripheral blood leukocytes using a commercial kit (EZ1 DNA Blood Kit, Qiagen, Hilden, Germany). The resulting DNAs were stored at $-20^{\circ} \mathrm{C}$ and the concentration measured in a Nanodrop ND-1000 spectrophotometer.

The PCR reactions for DRD4 gene (48 bp VNTR polymorphism in exon 3) contained $0.5 \mu \mathrm{M}$ forward primer (5'-GCGACTACGTGGTCTACTCG-3'), $0.5 \mu \mathrm{M}$ reverse primer (5'-AGGACCCTCATGGCCTTG-3'), $200 \mu \mathrm{M}$ of each deoxyribonucleotide triphosphate (dNTP) (deoxyguanosine triphosphate [dGTP] used as $100 \mu \mathrm{M}$ dGTP and $100 \mu \mathrm{M}$ deaza-GTP), $2.5 \mathrm{mM}$ magnesium chloride $\left(\mathrm{MgCl}_{2}\right), 0.25$ units TaqDNA polymerase (GeneDireX
MB-101), and 50 ng DNA template in a total volume of $25 \mu \mathrm{L}$. PCR conditions for the DRD4 gene were as follows: initial denaturation at $95^{\circ} \mathrm{C}$ for $15 \mathrm{~min}, 40$ cycles of 1 min denaturation at $94{ }^{\circ} \mathrm{C}, 1 \mathrm{~min}$ annealing at $55^{\circ} \mathrm{C}$, $1 \mathrm{~min}$ extension at $72^{\circ} \mathrm{C}$, and one final extension of $10 \mathrm{~min}$ at $72{ }^{\circ} \mathrm{C}$. The PCR reactions for DAT1 (40 bp VNTR polymorphism in $3^{\prime}$ UTR) contained $0.5 \mu \mathrm{M}$ forward primer (5'-TGTGGTGTAGGGAACGGCCTGAG-3'), $0.5 \mu \mathrm{M}$ reverse primer (5'-CTTCCTGGAGGTCACGGCTCAAGG-3'), $200 \mu \mathrm{M}$ dNTPs, $2.5 \mathrm{mM} \mathrm{MgCl}_{2}$, TaqDNA polymerase (GeneDireX MB-101), and $50 \mathrm{ng}$ DNA template in a total volume of $25 \mu \mathrm{L}$. PCR conditions for DAT1 were as follows: initial denaturation at $94{ }^{\circ} \mathrm{C}$ for $5 \mathrm{~min}, 35$ cycles of $20 \mathrm{~s}$ denaturation at $94{ }^{\circ} \mathrm{C}, 30 \mathrm{~s}$ annealing at $57^{\circ} \mathrm{C}, 20 \mathrm{~s}$ extension at $72{ }^{\circ} \mathrm{C}$, and one final extension of $5 \mathrm{~min}$ at $72^{\circ} \mathrm{C}$. All PCR reactions were carried out in a SimpliAmp thermal cycler (Applied Biosystems). The PCR products were then electrophoresed on a $2 \%$ agarose gel. Ethidium bromide was used for dying gels, which were then screened for genotyping.

\section{Statistical analyses}

Quantitative data were reported as mean \pm SD, while qualitative data were reported as observed frequencies and percentages. The Shapiro-Wilk test was used to verify the assumption of normality in groups and, according to the results, suitable parametric or nonparametric statistical tests were performed. Analysis of variance (ANOVA) or the Kruskal-Wallis test (nonparametric alternative) were used to compare study groups in a quantitative variable. If the Kruskal-Wallis test was statistically significant, Dunn's test was performed for pairwise multiple comparisons with Bonferroni correction. The chi-square method was applied to test for association between qualitative variables. When the result of the chi-square test was found significant for $r \times c$ tables, Bonferroni correction was used to control the familywise error rate in multiple comparisons. For the effect size, Cohen's $w$ was calculated with the formula $w=\sqrt{\chi^{2} / N}$.

Hardy-Weinberg equilibrium was analyzed for the DRD4 gene with eight observed alleles $(2 \mathrm{R}, 3 \mathrm{R}, 4 \mathrm{R}$, $5 R, 6 R, 7 R, 8 R, 9 R$ ) and their 36 possible genotypes, and likewise for $D A T 1$ with six observed alleles $(7 \mathrm{R}, 8 \mathrm{R}, 9 \mathrm{R}$, $10 \mathrm{R}, 11 \mathrm{R}, 12 \mathrm{R}$ ) and their 21 possible genotypes. The full set of alleles was not observed in each group; therefore, equilibrium was tested in each group separately with an exact test by using web-based $R$ software (version 3.5.2; package: HardyWeinberg; function: HWPerm.mult). ${ }^{30,31}$

All other statistical analyses were performed in IBM SPSS version 25.0. The level of significance was set at 0.05 .

\section{Ethics statement}

The ethics committee of Ege University approved the study protocol (protocol 16-5.2/2, 27 July 2016). All parents provided written informed consent.

\section{Results}

We compared the sociodemographic profiles, neurocognitive test performance, and genotypes our 31 subjects 
with SCT but no ADHD, 67 subjects with SCT and ADHD, 146 subjects with ADHD but no SCT, and 92 TD controls.

The sociodemographic variables of interest were age, gender, and parental education (Table 1). There was no statistically significant difference in mean age between groups, as determined by one-way ANOVA ( $p=0.917$ ). The female/male ratio was 1 for the SCT without ADHD group, 0.42 for the SCT + ADHD group, 0.26 for the ADHD without SCT group, and 0.76 for the TD group. We detected a significantly higher female prevalence in the SCT without ADHD group $(p<0.001)$. There were significant differences regarding paternal and maternal education across the groups $(p<0.001$ and $p=0.002$, respectively); namely, parents of participants in the SCT without ADHD and SCT + ADHD groups had lower educational attainment than those in the ADHD without SCT and TD groups.
In terms of neuropsychological test performance, the SCT without ADHD, SCT + ADHD, and ADHD without SCT groups scored significantly lower than the TD group on $\mathrm{NCl}$, memory, reaction time, cognitive flexibility, complex attention, and omission errors (Table 2). Although both the ADHD without SCT and SCT + ADHD groups had lower scores on psychomotor speed and commission errors than controls, the SCT without ADHD group did not differ in these two indexes compared to TD controls (Table 2).

Hardy-Weinberg equilibrium for the DRD4 gene was found in the SCT without ADHD and SCT + ADHD groups ( $p=0.422$ and $p=0.477$, respectively). On the other hand, in the ADHD without SCT and TD groups, disequilibrium was found $(p<0.001$ and $p<0.001$, respectively). The DAT1 gene was also in Hardy-Weinberg equilibrium in the SCT without ADHD and SCT + ADHD groups ( $p=0.627$ and $p=0.323$, respectively),

Table 1 Distribution of age, gender, and parental education among groups

\begin{tabular}{|c|c|c|c|c|c|}
\hline Sociodemographic characteristics & SCT w/o ADHD $(n=31)$ & $\mathrm{SCT}+\mathrm{ADHD}(\mathrm{n}=67)$ & ADHD w/o SCT $(n=146)$ & TD $(n=92)$ & p-value \\
\hline Age, years (mean $\pm S D$ ) & $10.39 \pm 2.48$ & $10.66 \pm 2.37$ & $10.64 \pm 1.93$ & $10.66 \pm 1.89$ & 0.917 \\
\hline Gender (female/male) & $16 / 15$ & $20 / 47$ & $31 / 115$ & $40 / 52$ & $<0.001$ \\
\hline Maternal education & & & & & $0.002 *$ \\
\hline No education & $0(0.0)$ & $2(3.1)$ & $0(0.0)$ & $1(1.1)$ & \\
\hline Primary & $15(48.4)$ & $27(42.2)$ & $45(30.8)$ & $34(37.0)$ & \\
\hline Secondary & $10(32.3)$ & $21(32.8)$ & 37 (25.3) & $13(14.1)$ & \\
\hline Higher & $6(19.4)$ & $14(19.4)$ & $64(43.8)$ & $44(47.8)$ & \\
\hline \multicolumn{6}{|l|}{ Paternal education } \\
\hline No education & $0(0.0)$ & $0(0.0)$ & $0(0.0)$ & $1(1.1)$ & $0.001 *$ \\
\hline Primary & $14(45.2)$ & $27(42.9)$ & $38(26.0)$ & $22(23.9)$ & \\
\hline Secondary & $11(35.5)$ & $22(34.9)$ & $34(23.3)$ & $21(22.8)$ & \\
\hline Higher & $6(19.4)$ & $14(22.2)$ & $74(50.7)$ & $48(52.2)$ & \\
\hline
\end{tabular}

Data presented as $\mathrm{n}(\%)$, unless otherwise specified.

$\mathrm{ADHD}=$ attention-deficit/hyperactivity disorder; $\mathrm{SCT}$ = sluggish cognitive tempo; $\mathrm{SD}$ = standard deviation; TD = typically developing controls; w/o = without.

* No parental education level was excluded from the analysis.

Table 2 Neuropsychological assessment (Computerized Neurocognitive Assessment and Continuous Performance Test) scores of the groups

\begin{tabular}{|c|c|c|c|c|c|c|}
\hline Neuropsychological findings & $\begin{array}{l}\text { SCT w/o ADHD } \\
(n=31)\end{array}$ & $\begin{array}{c}\mathrm{SCT}+\mathrm{ADHD} \\
(\mathrm{n}=67)\end{array}$ & $\begin{array}{c}\text { ADHD w/o SCT } \\
(n=146)\end{array}$ & $\begin{array}{c}\text { TD } \\
(n=92)\end{array}$ & $p$-value & Group comparisons \\
\hline \multicolumn{7}{|l|}{ CNSVS domain score } \\
\hline Neurocognition Index & $83.1 \pm 12.5$ & $79.2 \pm 13.8$ & $81.2 \pm 11.6$ & $98.3 \pm 12.8$ & $<0.001$ & All groups $<$ TD \\
\hline Total memory score & $81.9 \pm 26.0$ & $81.9 \pm 25.2$ & $84.9 \pm 21.4$ & $96.7 \pm 18.1$ & $<0.001$ & All groups < TD \\
\hline Psychomotor speed score & $92.8 \pm 11.7$ & $89.4 \pm 12.5$ & $84.7 \pm 17.5$ & $102.6 \pm 18.5$ & $<0.001$ & $\begin{array}{l}\text { ADHD w/o SCT and } \\
\text { SCT }+ \text { ADHD }<\text { TD }\end{array}$ \\
\hline Reaction time score & $70.1 \pm 17.7$ & $73.4 \pm 24.5$ & $73.5 \pm 25.1$ & $82.9 \pm 33.3$ & $<0.001$ & All groups < TD \\
\hline Complex attention score & $85.7 \pm 17.4$ & $70.6 \pm 32.7$ & $77.6 \pm 20.0$ & $104.2 \pm 13.5$ & $<0.001$ & All groups < TD \\
\hline Cognitive flexibility score & $84.1 \pm 19.4$ & $79.3 \pm 14.8$ & $85.4 \pm 13.1$ & $105.2 \pm 17.5$ & $<0.001$ & All groups < TD \\
\hline \multicolumn{7}{|l|}{ CPT } \\
\hline Correct hits & $37.6 \pm 2.4$ & $37.4 \pm 3$ & $35.8 \pm 4.5$ & $39.2 \pm 1$ & $<0.001$ & All groups $<$ TD \\
\hline Omission errors & $2.3 \pm 2.4$ & $2.5 \pm 3$ & $3.9 \pm 3.9$ & $0.7 \pm 1.9$ & $<0.001$ & TD $<$ All groups \\
\hline Commission errors & $3.7 \pm 4.8$ & $7.4 \pm 12.3$ & $5.9 \pm 7.5$ & $1.5 \pm 1.6$ & $<0.001$ & TD $<$ All groups \\
\hline Reaction time score & $590.2 \pm 168.1$ & $579.2 \pm 90.3$ & $527.7 \pm 85.4$ & $477 \pm 76.5$ & $<0.001$ & $\begin{array}{c}\text { TD }<\text { All groups ADHD w/o } \\
\text { SCT }<\text { SCT }+ \text { ADHD }\end{array}$ \\
\hline Test time & $28.1 \pm 2.8$ & $27.8 \pm 2.6$ & $26.6 \pm 2.0$ & $23.3 \pm 1.6$ & $<0.001$ & TD $<$ All groups \\
\hline
\end{tabular}

Data presented as mean \pm standard deviation.

$\mathrm{ADHD}=$ attention-deficit/hyperactivity disorder; CNSVS = Computerized Neurocognitive Assessment - Vital Signs; CPT = Continuous

Performance Test; SCT = sluggish cognitive tempo; TD = typically developing controls; $\mathrm{w} / \mathrm{o}=$ without. 
Table 3 Distribution of allele repeat numbers of the 40-bp VNTR in the DAT1 $3^{\prime}$ UTR and 48-bp VNTR region in exon 3 of DRD4

\begin{tabular}{|c|c|c|c|c|c|c|c|}
\hline Genetics findings & $\begin{array}{c}\text { SCT w/o ADHD } \\
(n=31)\end{array}$ & $\begin{array}{c}\mathrm{SCT}+\mathrm{ADHD} \\
(\mathrm{n}=67)\end{array}$ & $\begin{array}{c}\text { ADHD w/o SCT } \\
(n=146)\end{array}$ & $\begin{array}{c}\text { TD } \\
(n=92)\end{array}$ & $p$-value & $\begin{array}{l}\text { Cohen's } w \\
\text { index }\end{array}$ & $\begin{array}{c}\text { Group } \\
\text { comparisons }\end{array}$ \\
\hline \multicolumn{8}{|l|}{ DRD4 genotype } \\
\hline At least one 7R allele & $9(29)$ & $15(22.4)$ & $14(9.6)$ & $14(15.2)$ & 0.014 & 0.178 & $\mathrm{ADHD}<\mathrm{SCT}$ \\
\hline $4 \mathrm{R} / 4 \mathrm{R}$ & $15(48.4)$ & $37(55.2)$ & $97(66.4)$ & $44(47.8)$ & 0.023 & 0.168 & $\mathrm{TD}<\mathrm{ADHD}$ \\
\hline \multicolumn{8}{|l|}{ DAT1 genotype } \\
\hline 10R homozygosity & $19(61.3)$ & $35(52.2)$ & $77(52.7)$ & 33 (35.9) & 0.025 & 0.167 & None \\
\hline
\end{tabular}

Data are presented as $n(\%)$.

$\mathrm{ADHD}=$ attention-deficit/hyperactivity disorder; bp = base pair; DAT1 = dopamine transporter gene; DRD4 = dopamine D4 receptor gene; SCT = sluggish cognitive tempo; TD = typically developing controls; UTR = untranslated region; VNTR = variable-number tandem repeats.

whereas equilibrium did not hold in the ADHD and TD groups ( $p<0.001$ and $p=0.002$, respectively).

$D A T 1$ and DRD4 genotypes differed significantly across groups $(p=0.025, p=0.023$, and $p=0.014$ with medium effect sizes) (Table 3 ). The prevalence of $10 \mathrm{R}$ homozygosity for the DAT1 gene was $61.3 \%$ in the SCT without ADHD group, $52.7 \%$ in the SCT + ADHD group, $52.2 \%$ in the ADHD without SCT group, and $35.9 \%$ in the TD group.

The prevalence of $4 \mathrm{R}$ homozygosity for the $D R D 4$ gene was $48.4 \%$ in the SCT without ADHD group, $55.2 \%$ in the SCT + ADHD group, 66.4\% in the ADHD without SCT group, and $47.8 \%$ in the TD group. The only significant difference was between the ADHD without SCT and TD groups ( $p=0.024, w=0.184$, medium effect size). The prevalence of the seven-repeat allele for the DRD4 gene across groups was $29 \%$ in the SCT without ADHD group, $22.4 \%$ in the SCT + ADHD group, $9.6 \%$ in the ADHD without SCT group, and $15.2 \%$ in the TD group. The SCT without ADHD group had a significantly higher prevalence of this allele than the ADHD without SCT group $(p=0.018, w=0.220$, medium effect size) (Table 3).

\section{Discussion}

This study compared the sociodemographic profiles, neurocognitive test performance, and genotypes of four groups of children and adolescents (SCT without ADHD, SCT + ADHD, ADHD without SCT, and TD controls). The SCT without ADHD group had a higher proportion of females and lower parental education compared to the ADHD without SCT group. SCT without ADHD subjects underperformed on neuropsychological tests (except for psychomotor speed and commission errors) compared to TD controls, and had the highest prevalence of the 7R allele for the DRD4 gene. However, the ADHD without SCT group performed significantly worse on all neuropsychological domains compared to TD controls.

The sociodemographic findings of the present study are in same line with those of an epidemiological study conducted by Barkley. ${ }^{27}$ In this previous study, the ADHD group included higher proportion of male children than the SCT group, and SCT subjects had lower socioeconomic status and parental education. Parental education for ADHD subjects was similar to that of TD controls.
Although both the ADHD without SCT and SCT + ADHD groups scored lower on psychomotor speed and commission errors than controls, the SCT without ADHD group did not differ in these two indexes when compared to TD controls. It is important to note that previous studies were unable to find an association between SCT symptoms and psychomotor speed. ${ }^{32-34}$ Psychomotor speed deficits are more likely to be related to inattention symptoms.

When the distribution of allele repeat numbers of the 40-bp VNTR in the DAT1 3' UTR was examined, 10R homozygosity was most prevalent in the SCT without ADHD group, with a rate of $61.3 \%$. There was no significant difference between the SCT and ADHD groups. The 10R/10R genotype has been identified as a risk factor in children with ADHD, whereas the 9R/10R genotype has been identified as a risk factor in adult ADHD subjects. $^{35}$ In a meta-analysis of adults diagnosed with ADHD, an association was found with the 9R allele. However, this trend disappeared after Bonferroni correction. $^{36} 10 \mathrm{R}$ homozygosity has been shown to increase DAT protein concentrations in the basal ganglia and to decrease the amount of dopamine in the synaptic range in ADHD. ${ }^{4}$ Pharmacogenetic studies have shown that $10 \mathrm{R}$ homozygosity is associated with a reduced response to methylphenidate treatment. ${ }^{7}$

When we examined the distribution of allele repeat numbers of the 48-bp VNTR region in exon 3 of DRD4, we found that $4 \mathrm{R}$ homozygosity was most prevalent in the ADHD without SCT group, followed by the SCT + ADHD group. SCT without ADHD group had the highest 7R allele frequency (significantly different from the ADHD without SCT group). A review of pharmacogenetic studies and meta-analyses shows that the $4 \mathrm{R} / 4 \mathrm{R}$ genotype is associated with increased methylphenidate treatment response in ADHD subjects compared to the 7R allele. ${ }^{7,37,38}$ On the other hand, the $7 \mathrm{R}$ allele is associated with decreased methylphenidate response, and it has been suggested that the $7 \mathrm{R}$ allele may constitute a protein product associated with reduced stimulation of intracellular signaling mechanisms. ${ }^{39}$

In addition to these previous studies, a meta-analysis of 36 studies (3,647 children) was conducted to investigate predictors of response to methylphenidate therapy. This meta-analysis found a significant relationship between methylphenidate response and two variants: a 10-repeat VNTR in DAT1 and a four-repeat VNTR in DRD4. 
Children with $4 \mathrm{R}$ homozygosity for the DRD4 gene presented a $66 \%$ increase in the odds of methylphenidate response. Conversely, the 7R allele was not significantly related to methylphenidate response. ${ }^{40}$

In addition to treatment response, the DRD4 gene has also been reported to play an important role in treatmentrelated side effects. In a previous study investigating preschool-age children receiving ADHD medication, the authors reported that carriers of the $7 \mathrm{R}$ allele showed a higher risk of side effects. It has since been argued that ADHD carrying the 7R allele may constitute a subgroup with distinct characteristics. ${ }^{8,9,41}$ Although associations between methylphenidate response and DRD4 and DAT1 were reported in the studies described above, there are also contrasting results. Some studies found negative associations between response to methylphenidate and genes involved in the dopaminergic and serotonergic systems. ${ }^{42,43}$ We might speculate whether the symptoms of SCT may be associated with a defective DRD4 product encoded by the 7R allele, which would determine a reduced response to methylphenidate, as indicated in the literature. This specific subgroup of ADHD subjects carrying the 7R allele, as suggested by some investigators, may be the SCT population. Therefore, future pharmacogenetic studies of ADHD are advised to investigate SCT symptoms as well.

In line with our hypothesis, studies have shown that patients with SCT symptoms are unresponsive to methylphenidate treatment, but respond better to atomoxetine. ${ }^{27,44,45}$ This decreased response of SCT symptoms to methylphenidate might be explained by presence of the 7R allele for $D R D 4$.

Although there is a wealth of information about SCT and how it differs from ADHD in the clinical setting, there is still relatively little research on etiological factors. Barkley suggested that SCT should be both renamed "concentration deficit disorder" and considered as a second inattention disorder. ${ }^{15}$ Future research should seek to elucidate neurobiological pathways in SCT and the genes and neurotransmitters involved in these pathways.

Our study was the first to investigate VNTRs in the $D A T 1$ and DRD4 genes and their potential association with SCT symptoms. However, our findings should be interpreted in the context of some limitations. Previous studies derived SCT subjects from ADHD samples; we aimed to investigate subjects with pure SCT instead. However, as these subjects were relatively hard to find, the SCT without ADHD group was smaller than the ADHD without SCT group. Some of our results might reflect an effect of the smaller sample size of the SCT without ADHD group. Furthermore, we suggested that reduced methylphenidate response in SCT without ADHD subjects may be caused by presence of the $7 R$ allele for the DRD4 gene, based on the existing literature. However, pharmacogenomics studies are needed to demonstrate this association directly.

\section{Acknowledgements}

This study was supported by the Ege University Scientific Research Projects Coordinator (TTU-2018-20009).

\section{Disclosure}

LAR has received grant/research support from, served as a consultant to, or served on the speakers' bureaus of Eli Lilly, Janssen, Medice, Novartis, and Shire; has received authorship royalties from Oxford Press and Artmed; has received travel grants from Shire to take part in the 2018 APA annual meeting, and from Novartis to take part in the 2017 World Federation of ADHD annual meeting; and the ADHD and Juvenile Bipolar Disorder Outpatient Programs chaired by him have received unrestricted educational and research support from Eli Lilly, Janssen, and Novartis. Eyüp Sabri Ercan is on advisory boards for Sanofi Turkey. The other authors report no conflicts of interest.

\section{References}

1 Faraone SV, Larsson H. Genetics of attention deficit hyperactivity disorder. Mol Psychiatry. 2019;24:562-75.

2 Cortese S. The neurobiology and genetics of Attention-Deficit/ Hyperactivity Disorder (ADHD): what every clinician should know Eur J Paediatr Neurol. 2012;16:422-33.

3 Faraone SV, Bonvicini C, Scassellati C. Biomarkers in the diagnosis of ADHD--promising directions. Curr Psychiatry Rep. 2014;16:497.

4 Cheon KA, Ryu YH, Kim JW, Cho DY. The homozygosity for 10repeat allele at dopamine transporter gene and dopamine transporter density in Korean children with attention deficit hyperactivity disorder: relating to treatment response to methylphenidate. Eur Neuropsychopharmacol. 2005;15:95-101.

5 Bellgrove MA, Hawi Z, Kirley A, Gill M, Robertson IH. Dissecting the attention deficit hyperactivity disorder (ADHD) phenotype: sustained attention, response variability and spatial attentional asymmetries in relation to dopamine transporter (DAT1) genotype. Neuropsychologia. 2005;43:1847-57.

6 Bellgrove MA, Barry E, Johnson KA, Cox M, Daibhis A, Daly M, et al. Spatial attentional bias as a marker of genetic risk, symptom severity, and stimulant response in ADHD. Neuropsychopharmacology. 2008;33:2536-45.

7 Froehlich TE, Epstein JN, Nick TG, Melguizo Castro MS, Stein MA, Brinkman WB, et al. Pharmacogenetic predictors of methylphenidate dose-response in attention-deficit/hyperactivity disorder. J Am Acad Child Adolesc Psychiatry. 2011;50:1129-39.e2.

8 Bruxel EM, Akutagava-Martins GC, Salatino-Oliveira A, Contini V, Kieling $\mathrm{C}$, Hutz $\mathrm{MH}$, et al. ADHD pharmacogenetics across the life cycle: new findings and perspectives. Am J Med Genet B Neuropsychiatr Genet. 2014;165B:263-82.

9 McGough JJ. Attention deficit hyperactivity disorder pharmacogenetics: the dopamine transporter and D4 receptor. Vol. 13. England: Pharmacogenomics; 2012. p. 365-8.

10 Demontis D, Walters RK, Martin J, Mattheisen M, Als TD, Agerbo E, et al. Discovery of the first genome-wide significant risk loci for attention deficit/hyperactivity disorder. Nat Genet. 2019;51:63-75.

11 Bonvicini C, Faraone SV, Scassellati C. Common and specific genes and peripheral biomarkers in children and adults with attention-deficit/hyperactivity disorder. World J Biol Psychiatry. 2018;19: 80-100.

12 Brookes KJ. The VNTR in complex disorders: the forgotten polymorphisms? A functional way forward? Genomics. 2013;101:273-81.

13 Becker SP, Leopold DR, Burns GL, Jarrett MA, Langberg JM, Marshall SA, et al. The internal, external, and diagnostic validity of sluggish cognitive tempo: a meta-analysis and critical review. J Am Acad Child Adolesc Psychiatry. 2016;55:163-78.

14 Camprodon-Rosanas E, Batlle S, Estrada-Prat X, Acena-Diaz M, Petrizan-Aleman A, Pujals E, et al. Sluggish cognitive tempo in a child and adolescent clinical outpatient setting. J Psychiatr Pract. 2016;22: 355-62.

15 Barkley RA. Sluggish cognitive tempo (concentration deficit disorder?): current status, future directions, and a plea to change the name. J Abnorm Child Psychol. 2014;42:117-25. 
16 Bauermeister JAJ, Barkley RA, Bauermeister JA, Martinez JV, McBurnett K. Validity of the sluggish cognitive tempo, inattention, and hyperactivity symptom dimensions: neuropsychological and psychosocial correlates. J Abnorm Child Psychol. 2012;40:683-97.

17 Belmar M, Servera M, Becker SP, Burns GL. Validity of sluggish cognitive tempo in south america: an Initial examination using mother and teacher ratings of chilean children. J Atten Disord. 2017;21:667-72.

18 Fassbender C, Krafft CE, Schweitzer JB. Differentiating SCT and inattentive symptoms in ADHD using fMRI measures of cognitive control. Neuroimage Clin. 2015;8:390-7.

19 Camprodon-Rosanas E, Pujol J, Martinez-Vilavella G, Blanco-Hinojo $\mathrm{L}$, Medrano-Martorell S, Batlle S, et al. Brain structure and function in school-aged children with sluggish cognitive tempo symptoms. J Am Acad Child Adolesc Psychiatry. 2019;58:256-66.

20 Moruzzi S, Rijsdijk F, Battaglia M. A twin study of the relationships among inattention, hyperactivity/impulsivity and sluggish cognitive tempo problems. J Abnorm Child Psychol. 2014;42:63-75.

21 American Psychiatric Association. Diagnostic and Statistical Manual of Mental Disorders, Fourth Edition (DSM-IV). Arlington: American Psychiatric Publishing; 1994.

22 Achenbach TM. Manual for the Child Behavior Checklist. Burlingt: Univ Vermont; 1991.

23 Erol N, Bengi-Arslan L, Akçakln M. The adaptation and standardization of the Child Behavior Checklist among 6-18 year-old Turkish children. In: Sergeant J,editor. Eunethydis: European approaches to hyperkinetic disorder.Zurich: Fotorotar; 1995. p. 97-113.

24 DuPaul GJ, Ervin RA, Hook CL, McGoey KE. Peer tutoring for children with attention deficit hyperactivity disorder: effects on classroom behavior and academic performance. J Appl Behav Anal. 1998;31:579-92.

25 Magnusson P, Smari J, Gretarsdottir H, Prandardottir H. Attentiondeficit/hyperactivity symptoms in Icelandic schoolchildren: assessment with the attention deficit/hyperactivity rating scale-IV. Scand J Psychol. 1999;40:301-6.

26 Ercan ES, Amado S, Somer O, Çıkoğlu S. Dikkat Eksikliği Hiperaktivite Bozukluğu ve Yıkıcı Davranım Bozuklukları İçin Bir Test Bataryası Geliştirme Çabası. Çocuk ve Gençlik Ruh Sağığı Derg. 2001;8:132-44.

27 Barkley RA. Distinguishing sluggish cognitive tempo from ADHD in children and adolescents: executive functioning, impairment, and comorbidity. J Clin Child Adolesc Psychol. 2013;42:161-73.

28 Fırat S, Ünsel-Bolat G, Gül H, Baytunca MB, Kardaş B, Ercan ES. Barkley child attention scale validity reliability study. J Psychiatry Neurol Sci. 2018;31:3.

29 Gualtieri CT, Johnson LG. Reliability and validity of a computerized neurocognitive test battery, CNS Vital Signs. Arch Clin Neuropsychol. 2006;21:623-43

30 Graffelman J, Weir BS. Multi-allelic exact tests for Hardy-Weinberg equilibrium that account for gender. Mol Ecol Resour. 2018;18: 461-73.
31 R Core Team. R: A language and environment for statistical computing. Vienna: R Foundation for Statistical Computing; 2013.

32 Bauermeister JJ, Barkley RA, Bauermeister JA, Martinez JV, McBurnett K. Validity of the sluggish cognitive tempo, inattention, and hyperactivity symptom dimensions: neuropsychological and psychosocial correlates. J Abnorm Child Psychol. 2012;40:683-97.

33 Wood WL, Potts HE, Lewandowski LJ, Lovett BJ. Sluggish cognitive tempo and speed of performance. J Atten Disord. 2017;21: 684-90.

34 Unsel-Bolat G, Ercan ES, Bolat H, Suren S, Bacanli A, Yazici KU, et al. Comparisons between sluggish cognitive tempo and ADHDrestrictive inattentive presentation phenotypes in a clinical ADHD sample. Atten Defic Hyperact Disord. 2019;11:363-72.

35 Klein M, van Donkelaar M, Verhoef E, Franke B. Imaging genetics in neurodevelopmental psychopathology. Am J Med Genet B Neuropsychiatr Genet. 2017;174:485-537.

36 Bonvicini C, Faraone SV, Scassellati C. Attention-deficit hyperactivity disorder in adults: a systematic review and meta-analysis of genetic, pharmacogenetic and biochemical studies. Mol Psychiatry. 2016;21: 1643.

37 Gizer IR, Ficks C, Waldman ID. Candidate gene studies of ADHD: a meta-analytic review. Hum Genet. 2009;126:51-90.

38 Opmeer EM, Kortekaas R, Aleman A. Depression and the role of genes involved in dopamine metabolism and signalling. Prog Neurobiol. 2010;92:112-33.

39 Ebstein RP. The molecular genetic architecture of human personality: beyond self-report questionnaires. Mol Psychiatry. 2006;11:427-45.

40 Myer NM, Boland JR, Faraone SV. Pharmacogenetics predictors of methylphenidate efficacy in childhood ADHD. Mol Psychiatry. 2018;23: 1929-36.

41 Faraone SV, Bonvicini C, Scassellati C. Biomarkers in the diagnosis of ADHD - promising directions. Curr Psychiatry Rep. 2014;16:497.

42 Contini V, Victor MM, Bertuzzi GP, Salgado CA, Picon FA, Grevet $\mathrm{EH}$, et al. No significant association between genetic variants in 7 candidate genes and response to methylphenidate treatment in adult patients with ADHD. J Clin Psychopharmacol. 2012;32: 820-3.

$43 \mathrm{Ji}$ HS, Paik KC, Park WS, Lim MH. No Association between the response to methylphenidate and DRD4 gene polymorphism in Korean attention deficit hyperactivity disorder: a case control study. Clin Psychopharmacol Neurosci. 2013;11:13-7.

44 Froehlich TE, McGough JJ, Stein MA. Progress and promise of attention-deficit hyperactivity disorder pharmacogenetics. CNS Drugs. 2010;24:99-117.

45 Wietecha L, Williams D, Shaywitz S, Shaywitz B, Hooper SR, Wigal $\mathrm{SB}$, et al. Atomoxetine improved attention in children and adolescents with attention-deficit/hyperactivity disorder and dyslexia in a 16 week, acute, randomized, double-blind trial. J Child Adolesc Psychopharmacol. 2013;23:605-13. 